\title{
SIMULATION OF MECHANICAL PROPERTIES OF CERAMIC PARTS PRODUCED BY ADDITIVE TECHNOLOGIES IN WIDE RANGE OF LOADING RATES
}

\author{
Vladimir A. Skripnyak ${ }^{1,2}$, Evgeniya G. Skripnyak ${ }^{1}$, Vladimir V. Skripnyak ${ }^{1}$, and \\ Irina K. Vaganova ${ }^{1}$ \\ ${ }^{1}$ National Research Tomsk State University \\ 36 Lenin Avenue, 634050 Tomsk, Russia \\ e-mail: skrp@ftf.tsu.ru \\ ${ }^{2}$ Institute of Strength Physics and Materials Sciences SB RAS \\ 2/4, pr. Akademicheskii, Tomsk, 634021, Russia \\ e-mail: skrp2006@yandex.ru
}

Keywords: Instructions, ECCOMAS Congress, Computational Methods, Engineering Sciences, Proceedings.

\begin{abstract}
The multiscale simulation approach was used to study the mechanical behavior of ceramic parts created by the selective laser sintering (SLS) technology. The goal of the research was studding the difference in the elastic moduli and dynamic strength of ceramic parts, manufactured by the high-temperature sintering and the selective laser sintering. The mechanical properties of ceramic parts were determined by statistic averaging of the results of multi scale computer simulations of representative volumes of materials under loadings. It was shown that the probability of the fracture of such parts under dynamic loading depends on the time history evolution of the distribution of local values of specific internal energy and the damage parameter on the mesoscale level. It was found that the stress threshold of the dynamic fracture beginning of ceramic bodies depends on the distribution of the pore sizes and not just on the average porosity.
\end{abstract}

\section{INTRODUCTION}

Additive manufacturing (AM) of ceramics is intensively expanding in recent years, an AM technologies are moving to the class of economically beneficial industrial technologies [1]. These AM technologies can all be applied to creation of complex shape ceramic parts from nano-sized ceramic powders. In accordance with the ISO/ASTM AM technology is usually classified in two groups. The group of "single-step" technology is considered as a group in which the geometry and material are created simultaneously.

Great interest is manifested by the improvement of "single-step" AM technologies of manufacturing of ceramic parts [1-8 ]. In recent years, the selective laser sintering (SLS) manufacturing processes have been used for the production of ceramic parts [2-8]. SLS is an additive 
manufacturing process for creating 3D parts with complex geometries because the use of powder bed SPS makes it possible to densify the UHTC composites at a lower temperature and in a shorter time compared with conventional techniques of high temperature pressing (HIP). The list of UHTC materials with melting temperatures above $\sim 3000 \mathrm{~K}$ is limited to perhaps 16 phases or compounds (Table I).

\begin{tabular}{|c|c|c|c|c|c|c|}
\hline $\begin{array}{c}\text { Phase / } \\
\text { /crystalline lattice }\end{array}$ & $\begin{array}{c}\text { Mass } \\
\text { density, } 10^{3} \\
\mathrm{~kg} / \mathrm{m}^{3}\end{array}$ & $\begin{array}{c}\text { Young's } \\
\text { modulus, } \\
\text { GPa }\end{array}$ & $\begin{array}{l}\text { Poisson's } \\
\text { ratio }\end{array}$ & $\begin{array}{c}\text { Linear } \\
\text { expansion } \\
\text { coefficient } \\
\left.10^{-6} \mathrm{~K}^{-1}\right) \text { in a } \\
\text { range }(293- \\
1300 \mathrm{~K}) \\
\end{array}$ & $\begin{array}{c}\text { Melting } \\
\text { temperature, } \\
\mathrm{T}_{\mathrm{m}}, \mathrm{K}\end{array}$ & $\begin{array}{l}\text { Debye } \\
\text { temperature, } \\
\Theta_{\mathrm{D}}, \mathrm{K}\end{array}$ \\
\hline $\begin{array}{c}\mathrm{HfB}_{2} / \\
\text { Hexagonal }\end{array}$ & 11.19 & 530 & 0.12 & 6.3 & 3653 & 690 \\
\hline $\begin{array}{l}\mathrm{HfC} / \\
\mathrm{FCC}\end{array}$ & 12.76 & $\begin{array}{c}352- \\
462\end{array}$ & 0.18 & 6.6 & 4173 & 680 \\
\hline $\begin{array}{l}\mathrm{HfN} / \\
\mathrm{FCC}\end{array}$ & 13.9 & 380 & 0.25 & 6.5 & 3658 & 684 \\
\hline $\begin{array}{c}\mathrm{ZrB}_{2} / \\
\text { Hexagonal }\end{array}$ & 6.10 & $450-500$ & 0.128 & $\begin{array}{l}5.9 \\
-6.5\end{array}$ & 3518 & 942 \\
\hline $\begin{array}{l}\mathrm{ZrC} / \\
\mathrm{FCC}\end{array}$ & 6.56 & 348 & 0.18 & 6.7 & 3673 & 744 \\
\hline $\begin{array}{l}\mathrm{ZrN} / \\
\mathrm{FCC}\end{array}$ & 7.29 & 510 & 0.25 & 6.7 & 3223 & 684 \\
\hline $\begin{array}{c}\mathrm{TiB}_{2} / \\
\text { Hexagonal }\end{array}$ & 4.52 & 575 & 0.14 & $\begin{array}{c}4.6 \\
-5.2\end{array}$ & 3498 & $\begin{array}{l}820- \\
1140\end{array}$ \\
\hline $\begin{array}{l}\text { TiC / } \\
\text { Cubic }\end{array}$ & 4.94 & $460-497$ & $0.19-0.25$ & 7.95-8.58 & 3373 & 916 \\
\hline $\begin{array}{l}\text { TiN / } \\
\text { FCC }\end{array}$ & 5.39 & $440-615$ & 0.12 & 9.35 & 3223 & 809 \\
\hline $\begin{array}{c}\mathrm{TaB}_{2} / \\
\text { Hexagonal }\end{array}$ & 12.54 & 551 & & 8.2 & 3313 & 1309 \\
\hline $\begin{array}{l}\mathrm{TaCl} \\
\text { Cubic }\end{array}$ & 14.50 & 472 & 0.1719 & 6.3 & 4073 & 776 \\
\hline $\begin{array}{c}\text { WC / } \\
\text { Hexagonal }\end{array}$ & 15.77 & $668-714$ & 0.24 & $3.85-3.9$ & 3143 & 779 \\
\hline $\begin{array}{l}\text { TaN / } \\
\text { Cubic }\end{array}$ & 14.30 & 466 & 0.246 & 8.31 & 2973 & \\
\hline $\begin{array}{c}\mathrm{SiC} / \\
\text { Polymorphic }\end{array}$ & 3.21 & 454 & 0.16 & 4.7 & 3093 & 1200 \\
\hline $\begin{array}{c}\mathrm{B}_{4} \mathrm{C} / \\
\text { Rhombohedral }\end{array}$ & 2.52 & $432-463$ & $0.15-0.18$ & 4.5 & 2718 & 1016 \\
\hline $\begin{array}{c}\mathrm{ZrO}_{2} / \\
\text { Polymorphic }\end{array}$ & 6.05 & 360 & $\begin{array}{c}0.303- \\
0.312\end{array}$ & 8.0-10.6 & 2973 & 590 \\
\hline $\begin{array}{c}\mathrm{Si}_{3} \mathrm{~N}_{4} / \\
\text { Polymorphic }\end{array}$ & 3.29 & $166-310$ & $\begin{array}{l}0.23- \\
0.276\end{array}$ & $2.64-3.3$ & $2661-2769$ & 1178 \\
\hline
\end{tabular}

Table 1. Mechanical and thermodynamic properties of UHTC [1-18]

The use of SLS allows creating new composite materials simultaneously with the manufacture of structural elements. Leu and co-authors (2008), Sun, and Gupta (2008), Pattnaik and co-authors (2012) showed the possibility of freeform parts fabrication of ultra-high tempera- 
ture ceramics (UHTC) based on the zirconium diboride by laser sintering [5, 6]. Liu and coauthors (2015) showed the possibility of laser sintering of $\mathrm{ZrO}_{2}$ parts [7]. Parts that are made of UHTC have high oxidation resistance and are used for nozzles, the leading edges of space vehicles re-entering the earth's atmosphere, cutting tools, bearings, igniters, and others.

The main problem in creating high strength UHTC is connected with difficulties of consolidation due to high melting point and low self-diffusion coefficient of borides, carbides, and nitrides phases.

Computer designing of ceramic parts produced by SLS method, we need to resolve two key tasks. The first task is ensuring the required dimensions of parts. The second task is to provide the required strength of ceramics for normative loading conditions. Various methods and models are applied for the solution of these problems at different scale levels.

On the macro-level, the architecture of sintered parts is designed by CAD/CAM technology and the laser scanning patterns. Complex shapes of ceramic parts with hollow structures can be fabricated by SLS. To predict the strength of ceramic parts, it is required to know the effective values of mechanical properties of material include the strength under tension and compression, crack resistance, and other characteristics.

Mechanical properties of sintered ceramics depend on the parameters of laser scanning and the properties of ceramic's powder [7,9]. For theoretical prediction of mechanical properties of sintered ceramics it is need models that must take into account certain determining factors, which include: residual stresses, grain size distributions, interface boundaries, cracks and pores distributions, formed during sintering.

In present study, this approach was used to develop a two-scale model. The mechanical characteristics of the ceramic material (elastic moduli, the Hugoniot elastic limit, the spall strength, etc.) are predicted using the results of computer simulation of response of model representative volume element (RVE) over a wide range of strain rates. Statistical-numerical RVE determination techniques discussed in [10,11].

Using a modified smoothed particle hydrodynamics (SPH) method made it possible to separately take into account the kinetics of damage accumulation at the micro - and mesoscale levels [12]. Damage and fracture of condensed phases at the micro level are described implicitly using a damage parameter. At the mesoscale level the formation of mesoscopic cracks was simulated.

This approach will enable to adequately consider the impact of a wide range of structural defects on mechanical properties of materials obtained by SLS method [13,14].

\section{MODEL OF MECHANICAL PROPERTIES OF CERAMICS PRODUCED BY ADDITIVE TECHNOLOGIES}

Mechanical properties of sintered ceramics under dynamic loads can be defined using simulation of mechanical response structured RVE of ceramics. Model representative volumes are proposed to create using the evaluations of residual stress, the parameters of the interface boundaries, the parameters of the distributions of cracks and pores. The dimensions of the representative volume should exceed a multiple of the largest size structures of pores, cracks, volumes of melted particles. Model RVE of sintered ceramics with porosity $\sim 0.05$ shown in Figure 1. A continuum approach was used for describing response of structured RVE at the mesoscale level. Data on the mechanical properties of ceramic phases, the sintering temperature are required for prediction of mechanical properties of sintered materials. Properties of material particles in this case are defined for volume of matter $\sim 1 \mu \mathrm{m}^{3}$. In ceramics, fabricated by SLS of submicron powders, the size of pores and cracks can range from tens of nanometers to tens of micrometers $[5,6,15$, and 16]. 


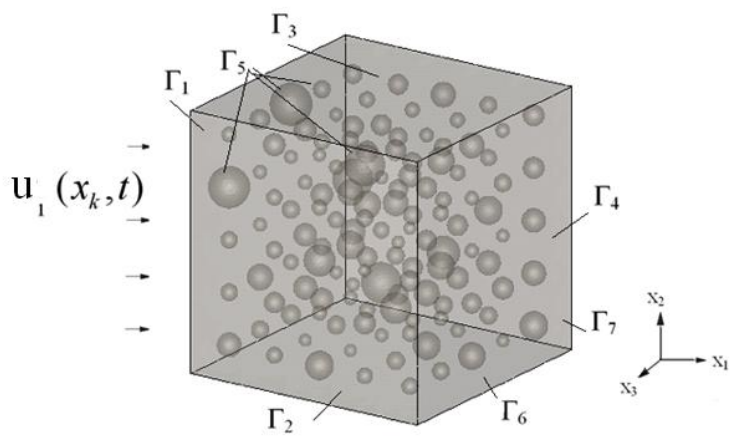

Figure 1. Model RVE and scheme of boundary conditions.

Pores and cracks with dimensions exceeding $\sim 1 \mu \mathrm{m}$ are set explicitly in the RVE. Their distribution in the RVE can be set randomly or taking into account the special distribution (for gradient or layered porous structures).The closed pores and penny shaped cracks of submicron size take into account implicitly by means of correction parameters of mechanical properties of material particles. In this case volumetric mass density and elastic moduli are defined by relations [17]:

$$
\rho=\rho_{t h}\left(1-\alpha_{0}\right), M \approx M_{t h}\left(1-\alpha_{0}\right),
$$

where $\rho$ is mass density, $\rho_{t h}$ is theoretical mass density of condensed phase, $\alpha_{0}$ is the specific volume of micro-pores, $M$ is the effective elastic modulus (the shear modulus, or the Young's modulus, or the bulk modulus) and $M_{t h}$ is the elastic modulus of the condensed phase.

Dynamics of structured media in RVE is described in Lagrangian coordinate system by mass conservation equation, momentum conservation equation energy and conservation equation $[18,19]$ :

$$
\underset{i}{\nabla} \sigma_{i j}=\rho \dot{u}_{i}, \dot{\rho}=\rho \underset{i}{\nabla} u_{i}, \rho \dot{E}_{\mathrm{int}}=\sigma_{i j} \dot{\varepsilon}_{i j},
$$

where $\sigma_{i j}$ is components of the Cauchy stress tensor, $\rho$ is mass density, $u_{i}$ are components of particle velocity vector, $\dot{\varepsilon}_{i j}$ are components of the strain rate tensor, $E_{\mathrm{int}}$ is the local specific internal energy per unit mas, the substantial derivative are market by dot notation.

Boundary conditions were applied to the cube-shaped RVE shown in Figure1.

$$
\begin{gathered}
u_{1}\left(x_{k}, t\right)=F\left(x_{k}, t\right) \quad x_{k} \in \Gamma_{1}, \\
u_{2}\left(x_{k}, t\right)=0, \quad x_{k} \in \Gamma_{2}, x_{k} \in \Gamma_{3}, u_{3}\left(x_{k}, t\right)=0, x_{k} \in \Gamma_{6}, x_{k} \in \Gamma_{7}, \\
p=u_{n}[\rho C]_{\Gamma_{4}} \text { for compression, or } u_{1}\left(x_{k}\right)=-F\left(x_{k}\right), \text { fortension, } x_{k} \in \Gamma_{4},
\end{gathered}
$$

where $\mathrm{C}$ is decreasing from longitudinal sound velocity in the elastic precursor to the bulk sound velocity $C_{B}, F\left(x_{k}, t\right)$ is a function for assigning a pulse shape and duration.

The initial conditions were used in the form:

$$
\rho\left(x_{k}\right)=\rho^{(0)}\left(x_{k}\right), \quad \varepsilon_{i j}\left(x_{k}\right)=\varepsilon_{i j}{ }^{(0)}\left(x_{k}\right), E\left(x_{k}\right)=E^{(0)}\left(x_{k}\right), D\left(x_{k}\right)=D^{(0)}\left(x_{k}\right),
$$

where $D$ is the damage parameter.

Residual stress is included in the model using eigenstrain $\varepsilon_{i j}{ }^{(0)}\left(x_{k}\right)$ [20]. Eigenstrain is an incompatible strains set up during sintering of a material. Residual stresses caused by thermal 
expansion mismatch between the randomly distributed microparticles of ceramic phases were introduces in the initial state of material particles.

The initial value of the damage parameter $\mathrm{D}^{(0}$ was determined by the method of homogenization to damages of a material particle containing a distribution of flaws [21].

Components of local strain rate tensor are defined by the relation:

$$
\dot{\varepsilon}_{i j}=\frac{1}{2}\left(\nabla_{i} u_{j}+\underset{j}{\nabla} u_{i}\right)
$$

where $u_{i}$ are components of velocity of material particles, $i=1,2,3, \underset{i}{\nabla}$ is the Hamilton operator.

The components of strain rates tensor is expressed by sum of the elastic and the inelastic parts:

$$
\dot{\varepsilon}_{i j}=\dot{\varepsilon}_{i j}^{e}+\dot{\varepsilon}_{i j}^{n}
$$

The constitutive equation of material particles is written in the form:

$$
\sigma_{i j}=\sigma_{i j}{ }^{(c)} \varphi(D), \sigma^{(c)}{ }_{i j}=-p^{(c)} \delta_{i j}+S_{i j}^{(c)},
$$

where $p$ is the pressure, $S_{i j}$ is the stress deviator tensor, the superscript $c$ indicates the condensed phase of the damaged material, $\varphi(D) \approx 1-D, D$ is the local damage parameter, and $\delta_{i j}$ is the Kronecker delta.

The local damage parameter $D$ is introduced in the form:

$$
D=\int_{0}^{t_{f}} \frac{\dot{\varepsilon}_{e q}^{n}}{\varepsilon_{f}^{n}} d t,
$$

where $\dot{\varepsilon}_{e q}^{n}=\left[(2 / 3) \dot{\varepsilon}_{i j}^{n} \dot{\varepsilon}_{i j}^{n}\right]^{1 / 2}$ denote an intensity of inelastic strain rate tensor, $\varepsilon_{f}{ }^{n}$ is the threshold of inelastic deformations of material particles (the volumes of the phases at the micro level) at fracture.

The growth of the damage parameter of the material particles implicitly reflects the degradation of the strength properties of phases due to nucleation and growth of microcracks. The criterion of local failure corresponds to $D=1$.

Threshold of effective shear strain $\varepsilon_{f}$ is approximated by relation:

$$
\varepsilon_{f}^{n}=D_{1}\left(P^{*}+T^{*}\right)^{D_{2}},
$$

where $T^{*}=\sigma_{s p} / P_{H E L}, P^{*}=p / P_{H E L}, P_{H E L}$ is pressure correspond to the Hugoniot elastic limit, $\sigma_{s p}=\left(3 \rho C_{l} \dot{\varepsilon}_{e q} K_{1 C}^{2}\right)^{1 / 3}, C_{l}$ is the longitudinal sound velocity, $D_{l}, D_{2}$ are material constants [19, 22].

Using the SPH-method, the formation of mesocrack described as the creation of spatial clusters of particles with broken bonds with neighboring particles [23].

In this case, the distance between neighboring particles should exceed the critical opening displacements at the crack tip $\delta^{*}$.

The critical opening smooth particle displacement was computed by Eqs (10) [24]:

$$
\delta=\left.r_{k l}\right|_{t}-\left.r_{l k}\right|_{t=0} \approx \delta^{*}, \delta^{*}=2 G_{f} / \sigma_{f}, 2 G_{f} \approx 2 K_{1 C}^{2} / E,
$$

where $r_{k l}$ is the current (at time t) distance between $\mathrm{k}$-th and l-th smoothed particles and $\delta *$ is the critical distance of the crack formation (corresponds to loss of interaction between particles), $G_{f}$ is the fracture energy, $\sigma_{f}$ is the thresholds stress of local brittle fracture. 
Macroscale fracture of RVE is characterized by complex temporal and spatial organizations of mesocracks. The thresholds stress of local brittle fracture for ceramics under compression $\sigma_{f}$ in wide range of strain rates can be described by Eqs. (10):

$$
\sigma_{f} / \sigma_{0}=1+\left(\dot{\varepsilon}_{e q} / \dot{\varepsilon}_{0}\right)^{2 / 3}, \sigma_{0}=4.25 K_{1 C} \eta^{1 / 4} /[\alpha]^{1 / 2}, \dot{\varepsilon}_{0}=4.25 K_{1 C} \eta^{3 / 4} /[\alpha \rho E]^{1 / 2},
$$

where $\alpha$ is a specific volume of voids, $\rho$ is the mass density, $K_{l C}$ is the fracture toughness, $E$ is the Young's modulus, and $\eta$ is a square density of unstable microcracks [25,26].

The thresholds stress of local brittle fracture for ceramic under tension at high strain rates described by Eq. (11):

$$
\sigma_{f s p}=\sigma_{t}+\left(3 \rho C_{l} \dot{\varepsilon}_{e q} K_{1 C}^{2}\right)^{1 / 3},
$$

where $\sigma_{t}$ is the quasi-static tensile strength.

Pressure calculated by Eqs (13):

$$
\begin{gathered}
p=p_{x}+\Gamma \rho_{0} E_{\mathrm{int}}^{T}, \\
p_{x}=\frac{3}{2} \cdot B_{0} \cdot\left(\xi^{-7 / 3}-\xi^{-5 / 3}\right) \cdot\left(1-\frac{3}{4}\left(4-B_{1}\right) \cdot\left(\xi^{-2 / 3}-1\right)\right) \text { for compression } \xi^{-1}-1>0, \\
p_{x}=B_{0} \xi^{-1}-1, \text { for tension } \xi^{-1}-1 \leq 0,
\end{gathered}
$$

where $\mathrm{B}_{0}, \mathrm{~B}_{1}$ are material constants, $\xi=\rho_{0} / \rho, \Gamma$ is a Gruneisen coefficient, $E_{\text {int }}^{T}$ is thermal part of a local specific internal energy per unit mass [27].

Shear micro-cracks nucleation in a condensed ceramic phase was accounted

$$
\frac{D\left[S_{i j}\right]^{(m)}}{D t}=2 \mu\left(\dot{\varepsilon}_{i j}^{e}-\frac{1}{3} \dot{\varepsilon}_{k k}^{e} \quad \delta_{i j}\right), \frac{D\left[S_{i j}\right]^{(m)}}{D t}=\left[\dot{S}_{i j}\right]^{(m)}-\left[S_{i k}\right]^{(m)} \dot{\omega}_{j k}-\left[S_{j k}\right]^{(m)} \dot{\omega}_{i k},(14
$$

where $\mu$ is the shear modulus.

$$
\dot{\varepsilon}_{i j}^{e}=\dot{\varepsilon}_{i j}-\dot{\varepsilon}_{i j}^{n}, \dot{\varepsilon}_{i j}^{n}=\dot{\lambda} \frac{\partial g}{\partial \sigma_{i j}}, g=\left[(3 / 2) S_{i j} S_{i j}\right]^{1 / 2}-\sigma_{f}(1-D),
$$

where $\dot{\lambda}$ is a model parameter.

The following parameters of $\mathrm{Eq}$ (11) for $\mathrm{ZrB}_{2}$ were used in the calculations: $\mathrm{ZrB}_{2}: E=495$ $\mathrm{GPa}, \rho=6.11103 \mathrm{~kg} / \mathrm{m}^{3}, K_{l C}=3.5 \mathrm{MPa} \mathrm{m}^{1 / 2}, \sigma_{H E L}=7.11 \mathrm{GPa}, p_{H E L}=3.07 \mathrm{GPa}, D_{l}=0.1, D_{2}$ $=1.0, C l=9.233 \mathrm{~km} / \mathrm{s}, \sigma_{f s p}=0.5 \mathrm{GPa}, \sigma_{s d}=0.5 \mathrm{GPa}$.

The values of the eigenstrain $\varepsilon_{i j}{ }^{(0)}\left(x_{k}\right)$ were assessed according to the estimated residual pressures that occur after cooling of sintering of ceramics. SLS of UHTC uses a sintering temperature from $1900 \mathrm{~K}$ to $2200 \mathrm{~K}$ [1-8].

The residual pressure was calculated by Eq.(16) [30]:

$$
p_{\text {res }}=\frac{2\left(\alpha_{m}-\alpha_{i n c}\right)\left(T-T_{r}\right) E_{m} E_{i n c}}{E_{\text {inc }}\left(1+v_{m}\right)+2 E_{m}\left(1-2 v_{i n c}\right)},
$$

where $p_{\text {res }}$ is the residual pressure, $\alpha_{m}, \alpha_{i n c}$ are the linear thermal expansion coefficients of matrix and inclusion, respectively, $T, T_{r}$ are the sintering temperature, and the room tempera- 
ture, $E_{m}, E_{i n c}, v_{m}, v_{i n c}$ is Young's modulus and Poisson's ratio; subscripts $m$ and inc correspond to matrix and inclusions, respectively.

The tensile stress decreases with the distance from the interface between grains of the matrix and the inclusion [30]:

$$
p_{\text {res }}=\frac{\left(\alpha_{m}-\alpha_{i n c}\right)\left(T-T_{r}\right) E_{m} E_{i n c}}{E_{i n c}\left(1-2 v_{m}\right)+2 E_{m}\left(1-2 v_{i n c}\right)}\left(\frac{d_{i n c}}{r+d_{i n c}}\right)^{3},
$$

where $d_{\text {inc }}$ is the size of the inclusion, and $r$ is the radial distance from the inclusion surface, respectively.

The increment of the fracture toughness $K_{I C}$ due to residual pressure can be estimated by the Eq. (18) [30]:

$$
\Delta K_{I C}=\frac{-2 C_{i n c} p_{r e s}}{1-C_{i n c}} \sqrt{\frac{2\left(L-d_{i n c}\right)}{\pi}},
$$

where $C_{i n c}$ is the volume fractions of inclusions, $L$ is the average distance between inclusions, $d_{\text {inc }}$ is the average size of inclusions, $p_{\text {res }}$ is the residual pressure in the matrix.

The fracture toughness $K_{l C}$ calculated using the residual pressure was used to determine the parameters $\sigma_{f}, \sigma_{0}, \dot{\varepsilon}_{0}$ in the $E q$. (11).

The mechanical properties of ceramics were determined by statistic averaging of the results of multi scale computer simulations of representative volumes of materials by method [19].

\section{RESULT AND DISCUSSION}

Figure 2 shows the thresholds stress of local brittle fracture for ceramics under compression versus normalized strain rates.

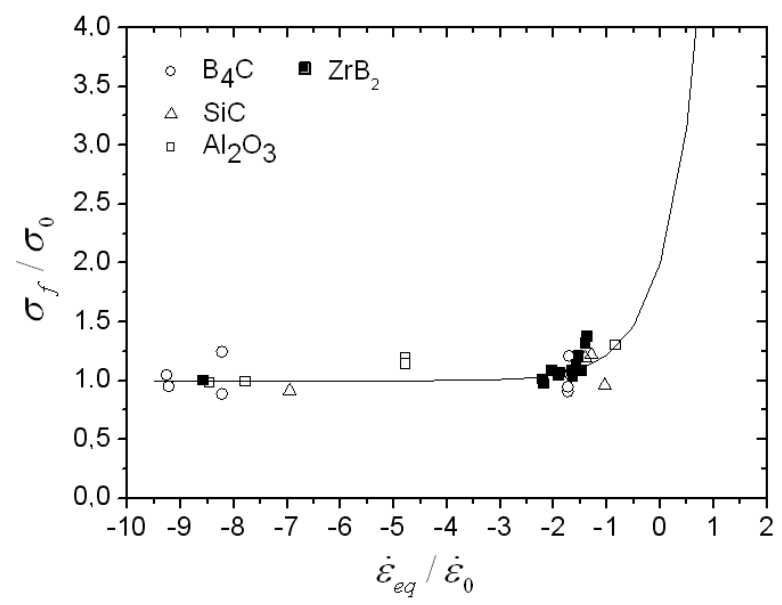

Figure 2. The thresholds stress of local brittle fracture for ceramics under compression versus normalized strain rates.

The characteristic stress and strain rate parameters for ceramics fabricated by hot isostatic pressing shown in Table 2 [25, 28, 33]. To predict the thresholds stress of quasi-brittle fracture under dynamic loading of ceramic bodies fabricated by additive technologies, including SLS, it is necessary to consider the impact the residual pressure, density and the size distribution of pores and flaws on the characteristic stress $\sigma_{0}$ and strain rate $\dot{\varepsilon}_{0}$ parameters. 


\begin{tabular}{lll}
\hline Material & $\sigma_{0}(\mathrm{GPa})$ & $\dot{\varepsilon}_{0}\left(s^{-1}\right)$ \\
\hline $\mathrm{B}_{4} \mathrm{C}$ & 3.4 & $10^{4}$ \\
$\mathrm{SiC}$ & 5.4 & $510^{3}$ \\
$\mathrm{ZrB}_{2}$ & 2.1 & $0.9510^{5}$ \\
$\mathrm{Al}_{2} \mathrm{O}_{3}$ & 3.05 & $9.010^{3}$ \\
\hline
\end{tabular}

Table 2. Characteristic stress and strain rate parameters for ceramics showed in Figure. 2.

Characteristic stress and strain rate parameters depend on the fracture toughness $K_{l C}$. The increase in the fracture toughness $K_{I C}$ may be due to residual pressure (see Eq.18).

Figure 3 shows the calculated by the $E q$. (17) residual pressure in nanocomposite $\mathrm{ZrB}_{2}$ ceramics versus difference of the maximum sintering temperature and the room temperature.

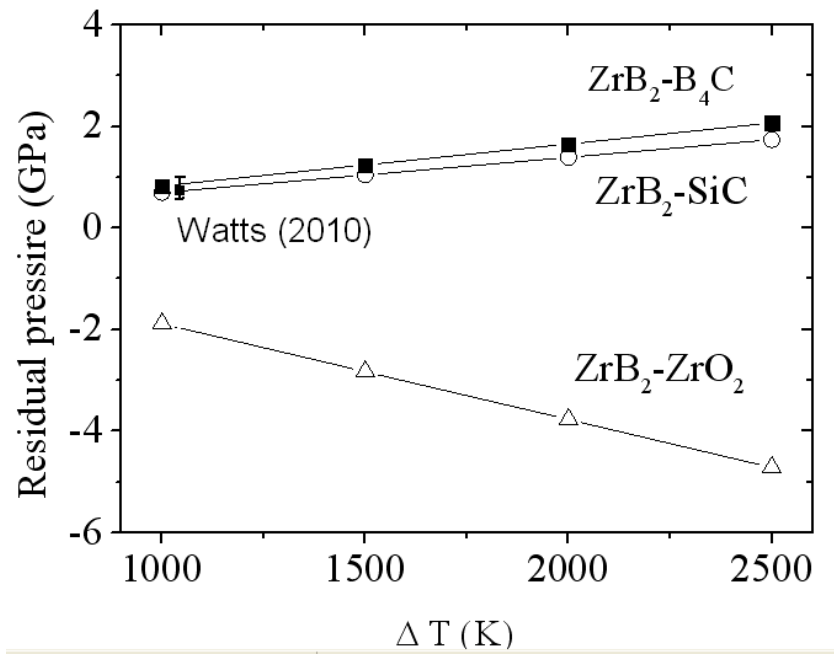

Figure 3. Residual pressure versus the cooling temperature.

Thermo-mechanical properties of matrix and potential inclusions are given in Table I. In multiphase system the residual pressures can be positive and negative. Recently Watts et al. have determined tensile residual stresses of $\sim 800 \mathrm{MPa}$ in the $\mathrm{ZrB}_{2}$ matrix of $\left(\mathrm{ZrB}_{2}-30\right.$ vol. $\mathrm{SiC})$ ceramics using Raman spectroscopy and neutron diffraction methods [29]. Calculated tensile stresses of $\sim 800 \mathrm{MPa}$ in the $\mathrm{ZrB}_{2}$ matrix near $\mathrm{SiC}$ inclusions is in good agree with experimental data $\sim 810 \mathrm{MPa}$ for $\mathrm{ZrB}_{2}-30$ vol. SiC [29].

Residual pressure varies linearly with difference of cooling temperature. Note, that the temperature rise caused by the energy density increasing during sintering and repeating laser scans. But as a result of increasing energy density in the sintering process not only increases the level of residual stresses, but reduces the pore size and porosity. Leu and co-authors showed that specimens of $\mathrm{ZrB}_{2}$ have lower porosity and smaller pores after SLS at the energy density of $0.115 \mathrm{~J} / \mathrm{mm}^{2}$ as compared to $0.103 \mathrm{~J} / \mathrm{mm}^{2}$ [5].

Katcoff and Graham-Brady presented the model for compressive dynamic failure of brittle materials with circular pore flaws, which incorporates both the number density and the size distribution of flaws [26].

For predicting the mechanical properties of ceramics fabricated by SLS under dynamic loading results of multi-scale computer simulation were used. Figure 4a shows SEM image of $\mathrm{Al}_{2} \mathrm{O}_{3}$ specimen fabricated by SLS [15]. Figure $4 \mathrm{~b}$ shows the distribution of damage parameter $D$ behind the front of a shock wave with amplitude of $7.2 \mathrm{GPa}$. 

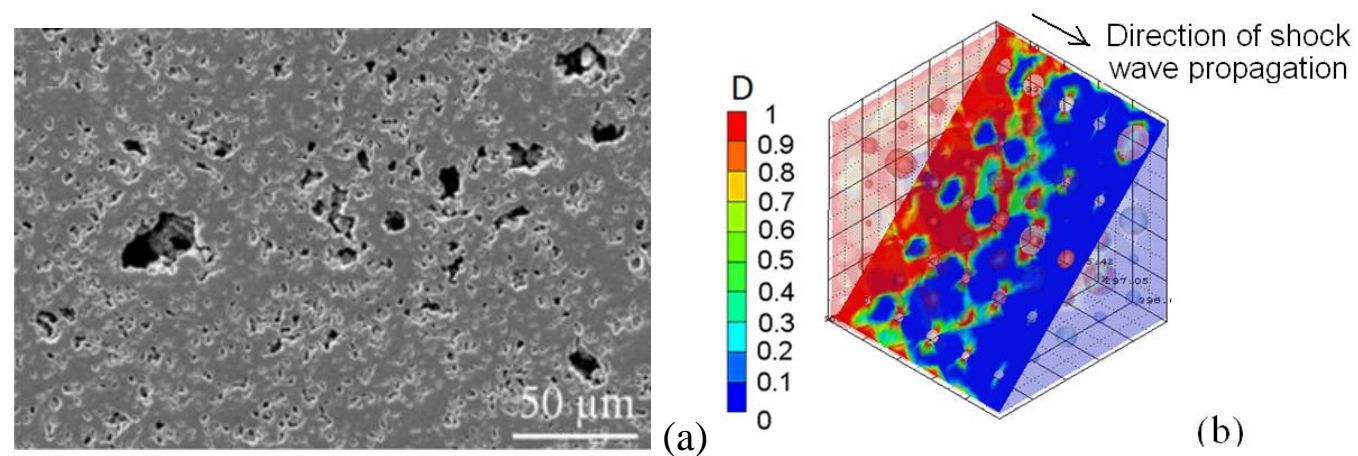

Figure 4. (a) SEM image of $\mathrm{Al}_{2} \mathrm{O}_{3}$ specimen fabricated by SLS [15]. (b) The distribution of damage parameter $\mathrm{D}$ behind the front of a shock wave with amplitude of $7.2 \mathrm{GPa}$.

The calculated average damage parameter versus time of shock compression of the samples of $\mathrm{Al}_{2} \mathrm{O}_{3}$ ceramics with a porosity of $5 \%$ is shown in Figure 5a. Dashed curve shows the time dependence of damage parameter for models with random pore size distribution (see Figure 1, $4 \mathrm{~b}$ ), and the solid curve is for a fixed pore size.
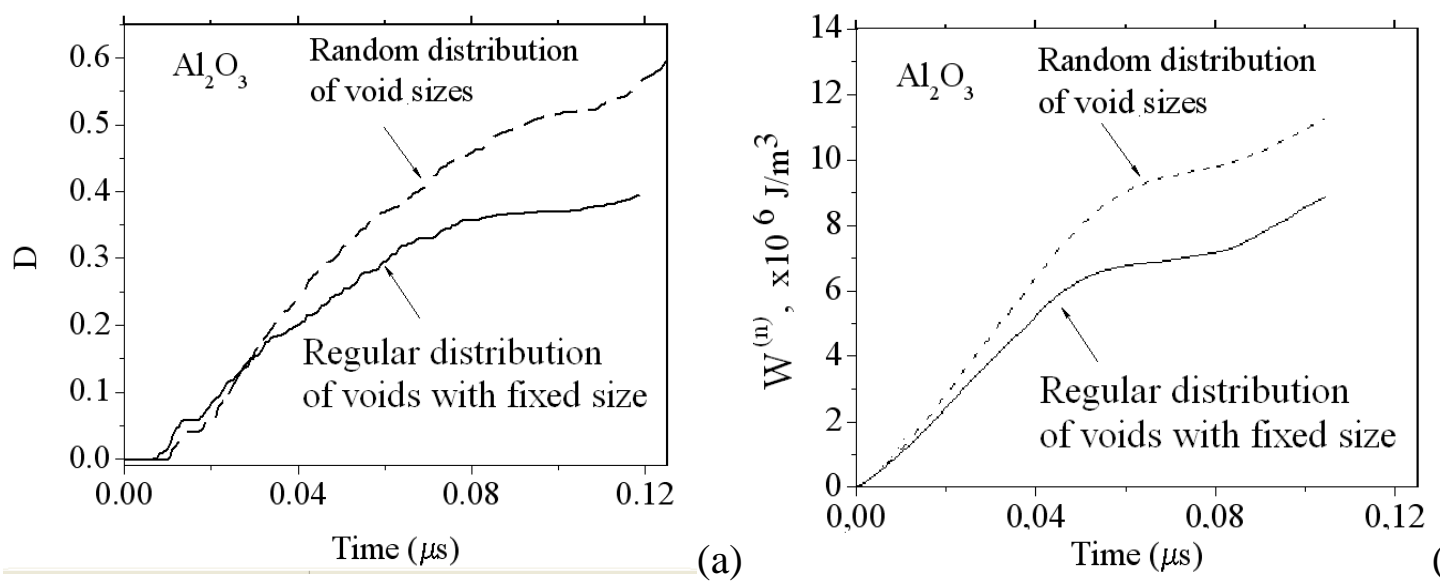

(b)

Figure 5. (a) Damage parameter of $\mathrm{Al}_{2} \mathrm{O}_{3}$ specimens behind the front of a shock wave with amplitude of 7.2 GPa versus time. (b) Specific work of stress on the inelastic deformation under shock compression versus time .

The distance between centers of neighboring pores in the models was equal to $100 \mu \mathrm{m}$. Therefore parts fabricated by SLS and having the same initial porosity will demonstrate a wide statistical distribution of the dynamic strength under the same loading conditions. Figure $4 \mathrm{~b}$ shows the specific work of stress on the inelastic deformation under shock compression versus time. The dissipative properties and also the specific internal energy will have wide distribution for ceramic parts fabricated by SLS due to distribution of pore sizes. The probability of the fracture of such parts under a dynamic loading depends on the time history evolution of a distribution of local values of specific internal energy and the damage parameter on the mesoscale level.

Figure 6 shows SEM image of $\mathrm{ZrB}_{2}$ specimen fabricated by SLS and calculated pressure and damage parameter behind the shock wave with an amplitude of $6.9 \mathrm{GPa}$. Collapse of pores is accompanied by pressure relaxation in the area surrounding the pores and the formation of cracks in the inter-porous space. Thus, the stress threshold of the dynamic fracture beginning of ceramic bodies depends on the distribution of the pore sizes and not just the average porosity. $\mathrm{Wu}$ and co-authors showed that the final microstructure and quality of the laser-sintered alumina powder beds are depended strongly on the laser parameters, such as laser power, laser scanning speed and laser beam size [31]. 

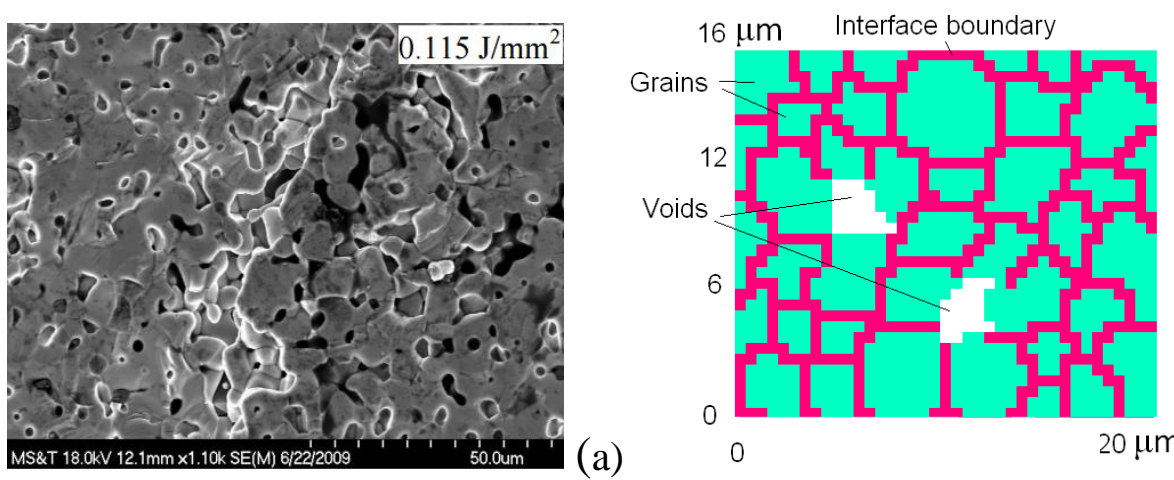

(b)
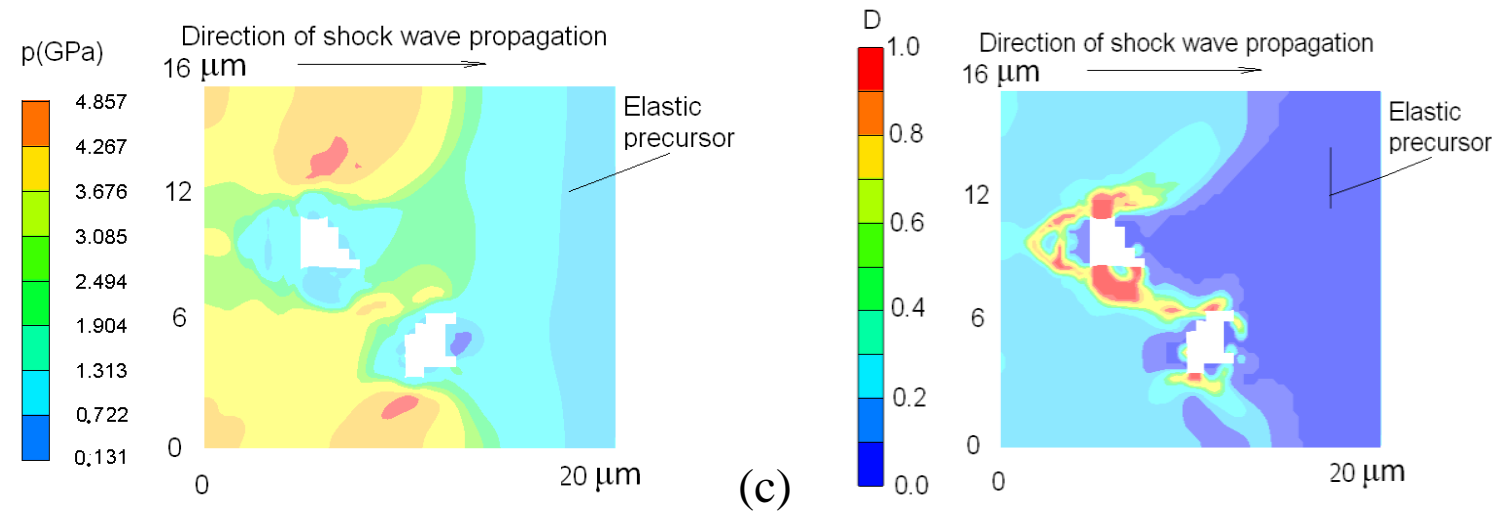

(d)

Figure 6. (a) SEM image of $\mathrm{ZrB}_{2}$ specimen fabricated by SLS [6]. (b) The cross section of the model RVE. (c) The pressure behind the shock wave with amplitude of $6.9 \mathrm{GPa}$. (d) The distribution of damage parameter behind the front of a shock wave with amplitude of $6.9 \mathrm{GPa}$.

Under short time laser-irradiation on the powder bed, the bonding particles can be ensured by solid-phase sintering. In this case the intergranular phase has a reduced strength compared with the phase of the particles. The multiscale simulation approach was used to study the mechanical behavior of ceramic parts created by the low energy SLS. Figure 7a shows the cross section of the model RVE of laser sintered $\mathrm{ZrB}_{2}$ ceramics.
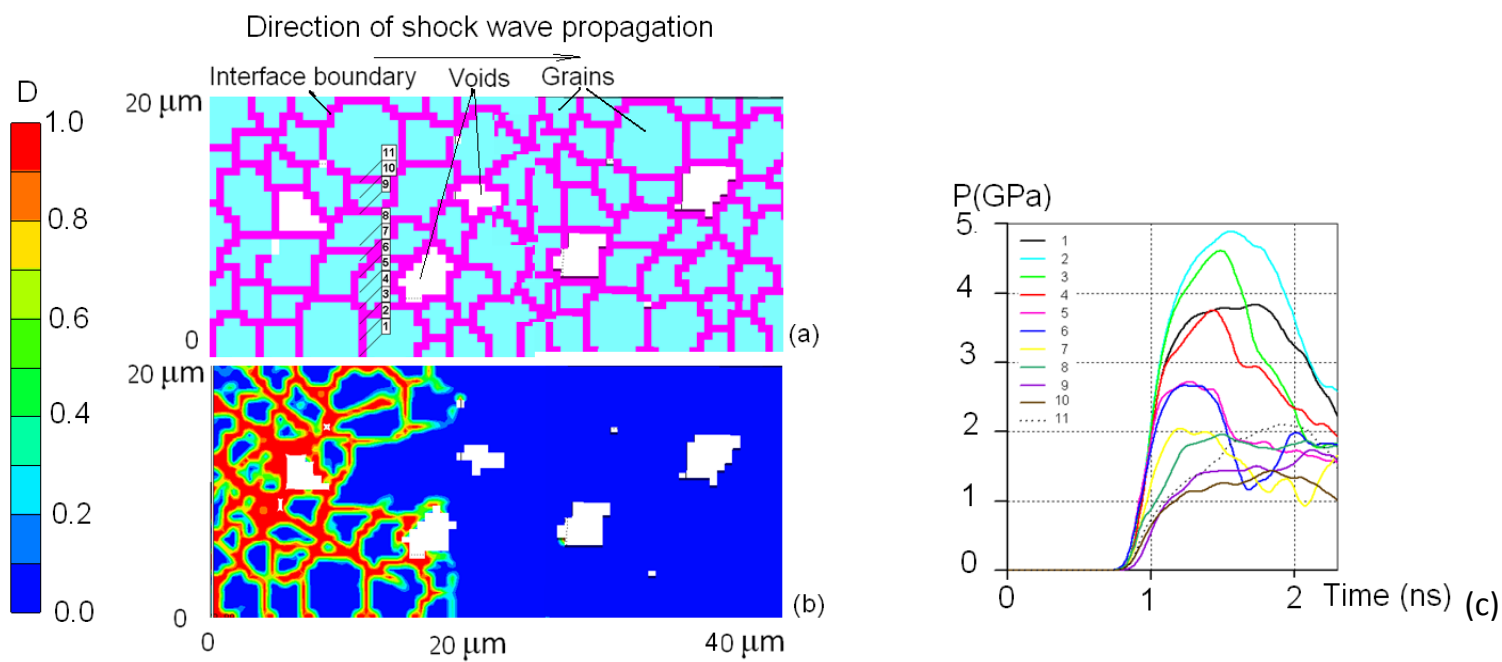

Figure 7. (a) The cross section of the model RVE. (b) The distribution of damage parameter behind the front of an elastic precursor. (c) Local pressure versus time in the points 1-11 (see Figure 6a). 
Figure $7 \mathrm{~b}$ shows the distribution of damage parameter behind the front of an elastic precursor. Figure 7(c) shows a temporal change of pressure in points behind front of the shock wave with amplitude of $7 \mathrm{GPa}$. Reviewed ceramics under dynamic compression damaged primarily at the interface boundaries. The damage is accompanied by energy dissipation and formation of fragments having dimensions comparable with the largest grain size of the powder. During compression the local pressure and the equivalent shear stress are described by distribution functions, whose parameters vary in time. Figure 8a,b show the probability densities of the normalized pressure in $\mathrm{ZrB}_{2}$ ceramics (see Figure 7c) at $1.5 \mathrm{~ns}$ and $2.2 \mathrm{~ns}$, respectively.
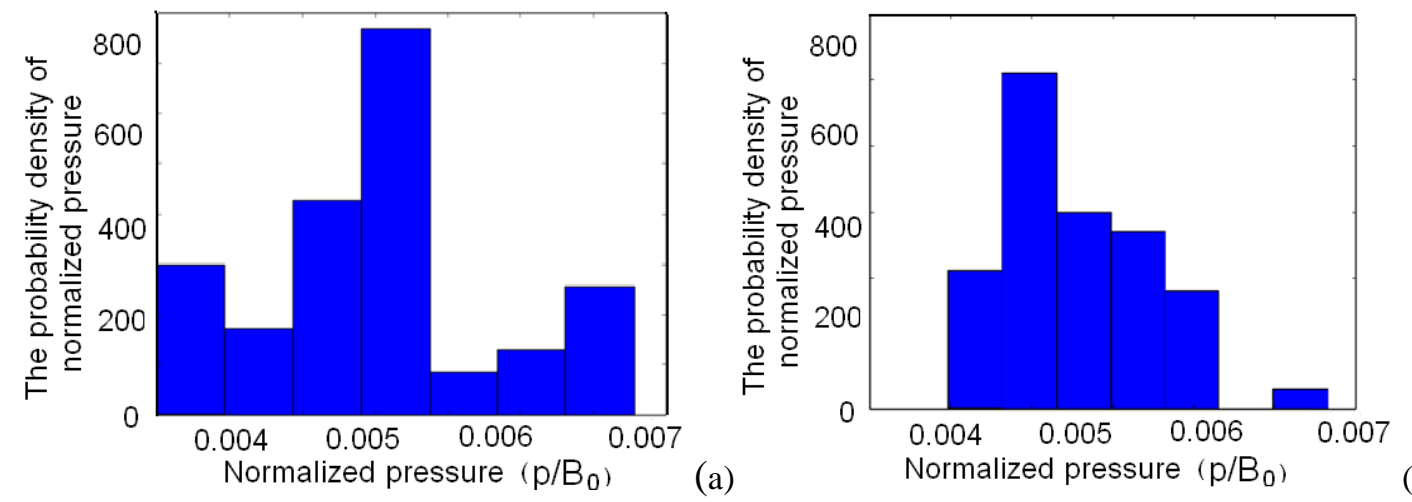

Figure 8. (a) The probability density of normalized pressure in $\mathrm{ZrB}_{2}$ ceramics. (b) The probability density of normalized pressure in $\mathrm{ZrB}_{2}$ ceramics.

The simulation results show the local and the average macroscopic values of stress can differ significantly under dynamic loading of laser sintered ceramics.

Since the damage and fracture always start at the micro-scale level, the prediction of the dynamic strength of parts fabricated by laser sintering requires additional data on the distribution of stresses in the materials on the mesoscale level. These data can be obtained using multiscale simulation.

The presented model can be used for examining the distribution of the state parameters and prediction of strength in the process of dynamic loading on parts and ceramic materials fabricated by additive technologies.

\section{CONCLUSIONS}

The multiscale simulation approach was used to study the mechanical behavior of ceramic parts created by the selective laser sintering (SLS) technology.

It was shown that the probability of the fracture of such parts under a dynamic loading depends on the time history evolution of a distribution of local values of specific internal energy and the damage parameter on the mesoscale level.

It was found that the stress threshold of the dynamic fracture beginning of ceramic bodies depends on the distribution of the pore sizes and not just on the average porosity.

The formation of frame structure by means of SLS allows increasing the dynamic limit of elasticity of the parts compared with ceramic materials with equivalent porosity.

\section{ACKNOWLEDGMENT}

This work was supported partially by the Grant from the President of Russian Federation, and by a grant from the Foundation of D. I. Mendeleev's National Tomsk State University 
within the Program of increasing the competitiveness of TSU. The authors are grateful for the support of this research.

\section{REFERENCES}

[1] J. Deckers, J. Vleugels, J.-P. Kruth, Additive manufacturing of ceramics: A review. Journal of Ceramic Science and Technology, 5, (4), 245-260, 2014.

[2] B. Qian, Z. Shen, Laser sintering of ceramics. Journal of Asian Ceramic Societies, 1, 315-321, 2013.

[3] N. Travitzky, A. Bonet, B. Dermeik, et al., Additive manufacturing of ceramic-based materials. Advanced engineering materials, 16, 729-754, 2014.

[4] M. Schwentenwein, and J. Homa, Additive manufacturing of dense alumina ceramics. International Journal Applied Ceramic Technology, 12, 1-7, 2014.

[5] S. Pattnaik, M. C. Leu, and G. E. Hilmas, Investigation of laser sintering for freeform fabrication of zirconium diboride parts. Virtual and Physical Prototyping, 7, 25-36, 2012.

[6] N.C. Sun, and M.C. Gupta, Laser sintering of $\mathrm{ZrB}$ 2. Journal of American Ceramic Society, 91 (5), 1729-1731, 2008.

[7] Q. Liu, Y. Danlos, B. Song, et al., Effect of high-temperature preheating on the selective laser melting of yttria-stabilized zirconia ceramic. Journal of Materials Processing Technology, 222, 61-74, 2015.

[8] G. N. Levy, R. Schindel, J.P. Kruth, Rapid manufacturing and rapid tooling with layer manufacturing $(\mathrm{lm})$ technologies, state of the art and future perspectives. CIRP Annals Manufacturing Technology, 52(2), 589-609, 2003.

[9] J. Xing, W. Sun, R.S. Rana, 3D modeling and testing of transient temperature in selective laser sintering (SLS) process. Optik, 124, 301-304, 2013.

[10] C. Pelissou, J. Baccou, Y. Monerie, F. Perales, Determination of the size of the representative volume element for random quasi-brittle composites. International Journal of Solids and Structures, 46, 2842-2855, 2009.

[11] T. D.P. Tran, S. D. Pang, S. T. Quek, Does representative volume element exist for quasi-brittle composites? Materials Science and Engineering A 528, 7757-7767, 2011.

[12] Parshikov A.N., Medin S.A., Loukashenko I.I., and Milekhin V.A., Improvements in SPH Method by means of interparticle contact algorithm and analysis of perforation tests at moderate projectile velocities. International Journal of Impact Engineering, 24, 779-796. 2000.

[13] R. Ganeriwala, T. I. Zohdi, Multiphysics modeling and simulation of selective laser sintering manufacturing processes. Procedia CIRP, 14, 299-304, 2014.

[14] S. A. Khairallah, A. Anderson, Mesoscopic simulation model of selective laser melting of stainless steel powder. Journal of Materials Processing Technology, 214, 2627-2636, 2014.

[15] K. Shahzad, J. Deckers, J. P. Kruth, J. Vleugels, Additive manufacturing of alumina parts by indirect selective laser sintering and post processing. Journal Materials Proc. Technology, 213, 1484-1494, 2013. 
[16] Y Wu, J Du, KL Choy, LL Hench, Laser densification of alumina powder beds generated using aerosol assisted spray deposition. Journal of the European Ceramic Society, 27 (16), 4727-4735, 2007.

[17] W. Pabst, E. Gregorova, G. Ticha, Elasticity of porous ceramics. A critical study of modulus-porosity relations. Journal of the European Ceramic Society, 26, 1085-1097, 2006.

[18] E. G. Skripnyak, V.A. Skripnyak, and V. V. Skripnyak, Fracture of nanoceramics with porous structure at shock wave loadings. M. D. Furnish et al. eds. Shock Compression of Condensed Matter -2011. AIP Conference Proceedings 1426, Melville, NY, 2012, 965 -970 .

[19] V.V. Skripnyak, E. G. Skripnyak, V. A.Skripnyak, and I.K. Vaganova, Computer simulation of fracture quasi-brittle ceramic nanocomposites under pulse loading. 11th. World Congress on Computational Mechanics (WCCM XI), Barcelona, Spain, June 25-29, 2014, Vol. IV, 3904-3914.

[20] T. S.Jun, A. M. Korsunsky, Evaluation of residual stresses and strains using the eigenstrain reconstruction method. International Journal of Solids and Structures, 47 (13), 1678-1686, 2010.

[21] A. L. Tonge, K.T. Ramesh, Multi-scale defect interactions in high-rate brittle material failure. PartI: Model formulation and application to ALON. Journal of the mechanics and physics of solids, 86, 117-149, 2016.

[22] T. J. Holmquist, G. R. Johnson, Response of silicon carbide to high velocity impact. Journal Applied Physics, 91 (9), 5858- 5866, 2002.

[23] S. Chakraborty, A. Shaw, A pseudo- spring based fracture model for SPH simulation of impact dynamics. International Journal of Impact Engineering , 58, 84-95, 2013.

[24] Y.V. Petrov, B.L. Karihaloo, V.V. Bratov, A.M. Bragov, Multi-scale dynamic fracture model for quasi-brittle materials. International Journal of Engineering Science, 61, 3-9, 2012 .

[25] J. Kimberley, K.T. Ramesh, N.P. Daphalapurkar, A scaling law for the dynamic strength of brittle solids. Acta Materialia, 61, 3509-3521, 2013.

[26] C.Z. Katcoff, L.L. Graham-Brady, Modeling dynamic brittle behavior of materials with circular flaws or pores International. Journal of Solids and Structures, 51, 754-766, 2014.

[27] A. L. Tonge, K.T. Ramesh Multi-scale defect interactions in high-rate brittle material failure. PartI: Model formulation and application to ALON. Journal of the mechanics and physics of solids, 86, 117-149, 2016.

[28] Vaganova I.K., Skripnyak V.A., Skripnyak V.V., Skripnyak E.G., Modeling of mechanical behavior of ceramic nanocomposites. Applied Mechanics and Materials, 756 , 187$195,2015$.

[29] J. Watts, G.E. Hilmas, W.G. Fahrenholtz, Stress measurements in $\mathrm{ZrB}_{2}-\mathrm{SiC}$ composites using Raman spectroscopy and neutron diffraction. Journal of European Ceramics Society, 30, 2165-2171, 2010. 
[30] J. W. Zimmermann, G.E. Hilmas, W.G. Fahrenholtz, Thermal shock resistance of $\mathrm{ZrB}_{2}$ and $\mathrm{ZrB}_{2}-30 \%$ SiC. Material Chemistry and Physics, 112, 140-145, 2008.

[31] Y. Wu, J Du, KL Choy, LL Hench, Laser densification of alumina powder beds generated using aerosol assisted spray deposition. Journal of the European Ceramic Society, 27 (16), 4727-4735, 2007.

[32] Q Liu, Y Danlos, B Song, et al., Effect of high-temperature preheating on the selective laser melting of yttria-stabilized zirconia ceramic. Journal of Materials Processing Technology, 222, 61-74, 2015.

[33] Skripnyak V.V., Skripnyak V.A., Vaganova I.K. et al. Multiscale simulation of porous quasi-brittle ceramics fracture. Applied Mechanics and Materials, 756, 196-204, 2015. 